\title{
UNA PUBLICACIÓN ROMÁNTICA OLVIDADA
}

A Ackermann se debe, entre otras novedades, la introducción en Inglaterra del almanaque literario alemán tan en boga durante el período romántico. El Forget me not, "a Christmas and New Year's present for 1829 ", colección de breves composiciones en prosa y verso de autores contemporáneos, fué el primero de estos libritos para el público inglés. Imitado en seguida por otros editores, en pocos años pulularon los annuals de Navidad, bellamente ilustrados y cuidadosamente impresos.

También de esta publicación decidió Ackermann hacer una adaptación española para los países hispanoamericanos. Así surgió el No me olvides, del que aparecieron seis volúmenes. Los cuatro primeros, de 1824 a 1827 , son obra de José Joaquín de Mora. Los dos últimós, correspondientes a 1828 y 1829 , de Pablo Mendíbil ${ }^{1}$.

Los No me olvides de Mora no están totalmente traducidos, ni mucho menos, del Forget me not inglés. Entre las composiciones en prosa hay pocas originales, pero las poéticas son casi todas del propio Mora. El primer volumen contiene unas treinta obras en verso y otras tantas en prosa; luego, la proporción se modifica al incluir narraciones más largas, pero el número de poesías sigue siendo casi el mismo. Mora, pues, publicó en su almanaque, antes de salir para la Argentina a principios de 1827 , como un centenar de poesías, de las cuales sólo una pequeña parte fué recogida por su autor en ediciones posteriores (Cádiz, 1836 ; Madrid, 1853 ).

El No me olvides de $1824^{2}$ es el que contiene menos traducciones. Para que pudiera estar a la venta antes de las Navidades de

${ }^{1}$ Los No me olvides son de una extrema rareza. El British Museum no posee más que el de 1824 . El de 1825 lo he consultado en la Columbia University de Nueva York. El de 1827 está en la biblioteca del Wagner Free Institute of Science de Filadelfia. Del No me olvides de 1828 tengo el ejemplar que me cedió don Pedro Salinas, adquirido hace años en México. Los de 1826 y 1829 , no registrados en ninguna biblioteca norteamericana, los posee don Vicente Salvá, biznieto del emigrado liberal del mismo nombre residente en Valencia, a quien me complazco en dar las gracias por haberme permitido utilizarlos.

${ }^{2}$ No me olvides: Colección de producciones en prosa y verso, originales y traducidas por José Joaquin de Mora. Londres. Lo publica R. Ackermann, 96, Strand, y en su establecimiento en Megico; asimismo en Colombia, en Buenos Aires, Chile, Peru y Goatemala. 1824. 380 págs. 
1823, Mora, que acababa de llegar a Londres, en vez de ponerse a traducir, aprovechó materiales propios, algunos de años muy anteriores. En la parte poética hay, por ejemplo, seis "Romances granadinos", dos de los cuales figuraban entre los que doña Frasquita Larrea de Boehl de Faber remitió entusiasmada a Guillermo Augusto de Schlegel en 1813, un año antes de que se rompieran las amistosas relaciones de Mora con los Boehl de Faber por culpa, al menos en apariencia, de las ideas de Schlegel ${ }^{3}$.

Hay de todos modos composiciones de procedencia inglesa, algunas traducidas a su vez del francés y del alemán; unashistoria rusa, una narración fantástica alemana y otra de Kotzebue, cuyo sentimen. talismo había hecho furor en Inglaterra; relatos de viajeros ingleses; descripciones alpinas, de templos góticos, de paisajes urbanos, como la descripción de Viena por Madame de Staël.

A estas páginas añadió Mora de su cosecha otras no menos variadas: anécdotas diversas, un breve ensayo sobre la belleza y el gusto, el estudio de algunos sinónimos castellanos, y dos narraciones: El paraguas, de ambiente granadino, y La audiencia y la visita.

La parte poética, además de los romances mencionados, comprende letrillas y epístolas satíricas, fábulas, composiciones pastoriles y piscatorias, canciones y dos poemas descriptivos.

El No me olvides de 1824 fué reseñado por Blanco White en su revista Variedades o el Mensajero de Londres ${ }^{4}$. La prosa de Mora le parece "elegante y fácil", y su poesía "se acerca varias veces a la realidad y sinceridad de sentimientos que echo de menos en casi toda la poesía española; y en general es agraciada, en el estilo usado". Blanco reproduce a continuación algunas composiciones, destacando una imitación de Virgilio, que empieza así:

Musgosa fuente que al vecino río
sonora envías tu raudal undoso;
y tú, blanda cual sueño venturoso,
yerba empapada en matinal rocío...

Es justamente el soneto que Menéndez Pelayo incluyó -siguiendo una versión posterior - en su antología Las cien mejores poesias liricas de la lengua castellana.

Lo más interesante, sin embargo, del artículo de Blanco White no es el breve juicio sobre la poesía de Mora, sino los consejos que se permite darle. Es indudable que a Blanco no le satisfacía aquel "estilo usado" de Mora vistiendo todavía el pellico pastoril ${ }^{5}$; pero

${ }^{3}$ Véase C. Pitollet, La querelle caldéronienne, págs. 77-79.

4 Julio de 1824 (vol. I, págs. 340-344).

5 De una de sus canciones dice que tiene "todo el mérito que admite un asunto de zagales y pastoras; bien que ya es tiempo de que los poetas españoles hablen en persona propia, y dexen el cayado y el pellico". No hará falta recordar 
reconocía en él, como en otros españoles, dotes poéticas indudables, que no necesitaban sino adecuado cultivo para obtener pleno desarrollo. Por eso considera oportuno alentarle a emprender un nuevo camino, después de varias consideraciones generales sobre la poesía española, que vale la pena reproducir:

El autor y compilador de No me olvides es uno de los españoles a quienes las disensiones políticas de España han obligado a refugiarse en Inglaterra, después (a lo que entiendo) que las revoluciones anteriores lo hubieron hecho vivir por bastante tiempo en Francia. Para un español de talentos, como los que el No me olvides demuestra en su autor, cualquier azar que lo saca del charco estancado de España es un acontecimiento feliz, por lo que hace a los intereses de la parte intelectual. La parte flaca de los literatos españoles que nunca han salido de su rincón es la vanidad que resulta naturalmente de la actividad y fuerza de alma que generalmente poseen, y de la pequeñísima esfera a que están reducidos. Faltos de libros, faltos de público que les excitase, que supiese apreciarlos, y que en su totalidad fuese superior a cualquier individuo por muy dotado que estuviese de la naturaleza, los pocos que en España dejaban el camino de las aulas por el de la literatura no tenían más mundo en que vivir que una pequeña sociedad de amigos, con quienes comunicaban sus ideas y de quienes recibían el aplauso con que mantenían en vida a su extenuada musa. ¿Qué podía resultar de esto? Lo que hemos visto: primicias de ingenio, preciosas en sí, pero sin jugo, sin fuerza, sin frondosidad: imitaciones de imitaciones, hasta la cuarta y quinta generación de copias. Faltábales a los autores libertad, campo ancho en que ejercerla, y caudal de ideas originales acopiadas por ellos mismos y no tomadas de mano de revendedores. Examínese cada cual de los que, con talentos e instrucción suficiente para adelantar, se vieron forzados a vivir prisioneros o desterrados en Francia, y no podrán negar que sus ideas se acrecentaron en número, se vigorizaron. desenvolviéndose, y perdieron cierta puerilidad, hija del encerramiento anterior, que acompañaba a no pocos españoles habilísimos hasta la sepultura.

Pero la España es desgraciada hasta en su posición geográfica, que la limita a un solo vecino, de quien ha derivado muchos males, y de quien si recibe algún bien es, por lo general, con mala mezcla. Dejemos aparte los daños políticos que de allí han venido, y demos una sola mirada a los literarios. La literatura francesa introducida con la casa de Borbón en España, dió la última mortal herida al genio nacional, que ya estaba enfermizo por el influjo de la literatura italiana. ¿Qué mala

que once años más tarde los románticos de El Artista en Madrid concentraban aún sus ataques contra la poesía pastoril neoclásica con sátiras como El pastor clasiquino de Espronceda. 
estrella ha hecho que el vigoroso ingenio español desde su juventud se haya esclavizado a una u otra musa extranjera? Hubiera en buen hora aprendido de la de Dante o de la de Ariosto a desplegar sus propias alas; mas ¿quién no se quejará al verlo ocupado en hacérselas de gasa, y pintarlas con colores prestados y mal embebidos, que se empeñó en exprimir de los cambiantes del Petrarca? ¿Quién lo verá sin pena cuando cansado de aquel empeño, vuelve los ojos al genio francés, y porque o lo ve falto de alas o porque, si alguna vez las usa, son como de mariposa, ora se arrastra por tierra, ora trisca y se revuelve con una viveza indecorosa y mal avenida con el contorno colosal de su figura?

Poquísimos son los escritos que entre los muy pocos no sofocados por la tiranía intelectual de España, no se resienten de uno u otro de estos dos vicios. La poesía mueve sus hinchados pies en grillos italianos; la prosa desfigura sus hermosas formas con corsés estrechos y mal fraguados, y deslustra su natural trigueño con parches de arrebol francés. De aquí es que a no ser cuando se atacan unos a otros, los escritores españoles apenas parece que hablan de veras. No nace esto de afectación, que se opone al gusto natural de los pueblos de la península; no es más que un cierto desgarbo y falta de libertad con que se presentan al público en vestidos ajenos y mal cortados.

La verdadera escuela de naturalidad es la Inglaterra, y si el autor del No me olvides, con lo que tiene adelantado hacia ella, se emplea en el estudio de los buenos autores británicos tanto en verso como en prosa, talentos tiene, sin duda, para dejarse atrás a muchos de los más afamados españoles ${ }^{6}$.

Estas y otras ideas literarias que Blanco fué exponiendo en su revista y en alguna publicación inglesa durante la primera mitad de 1824 , nada tenían de común con las sustentadas por Mora hasta fecha muy reciente. Sin embargo, poco después -agosto y septiembre del mismo año- Mora se hacía eco de ellas en sus artículos sobre poesía castellana de la European Review ${ }^{7}$.

Por otra parte, tampoco desatendió las indicaciones de Blanco acerca de su propia obra. En el prólogo del siguiente No me olvides $^{8}$, nos encontramos con estas palabras:

El editor [autor] ha mirado con particular esmero los artículos de poesía, movido por el estímulo que le ha dado la aprobación con que han favorecido las composiciones poéticas del primer número algunos sujetos inteligentes, y especialmente el distinguido literato a cuya pluma debe el Mensajero de Lon-

- Variedades o el Mensajero de Londres, vol. I, págs. 341-342.

"Vol. I, págs. $373-383$ y $53^{1-54}$.

${ }^{8}$ No me olvides: Colección de producciones... Ackermann, Londres, 1825; IV +382 págs. 
dres la justa fama de que goza. El editor ha seguido el consejo de este profundo humanista; ha procurado en sus composiciones serias impregnarse del gusto y del carácter dominante de la poesía inglesa, y si no se ha atrevido a grandes innovaciones, ni a sacudir de un todo el yugo de los modelos que su educación literaria lo han acostumbrado a respetar, no es por falta de deseos ni de convencimiento, sino porque cree que semejantes reformas son infructuosas cuando no las sanciona una reputación justamente acreditada.

En realidad, Mora, si es que entendió del todo el consejo de Blanco, no lo siguió fielmente. Lo que Blanco quiso decir (aunque en el pasaje mencionado no fuera tan explícito como en otros), no es que imitara la poesía inglesa, sino que la estudiara. Sustituir una imitación por otra, la francesa por la inglesa, era igualmente contrario al concepto romántico de que cada genio nacional tiene sus peculiares e inimitables formas de expresión. La poesía española había perdido su gracia y su vigor antiguos por dejarse llevar de italianos y franceses en vez de expresarse con naturalidad, esto es con sinceridad. Si el estudio de la literatura inglesa, menos sujeta a reglas y principios de escuela que otras, le parecía a Blanco recomendable y aun necesaria para un español, no era por considerarla simplemente digna de imitación, sino más bien como ejemplo a seguir.

El caso es que Mora se separa por primera vez de sus modelos tradicionales, al mismo tiempo que nos ofrece, aunque tímidamente, ciertas innovaciones dentro del gusto poético inglés. ¿En qué consisten? De momento, dice el autor, sólo afectan a las "composiciones serias". Y de éstas, podemos añadir nosotros, hay algunas que no revelan la menor alteración, por ejemplo, las odas morales a la manera de fray Luis de León, el poeta predilecto de Mora, cuya influencia no le abandonó nunca. En cambio hay una breve Imitación de Shakespeare y un romance, Zulema, cuya novedad principal consiste en que la morisca española que da título a la composición se ha convertido en una Ofelia septentrional y romántica.

Algo nuevo hay también en otras poesías. El estilo pastoril ha desaparecido, y en las composiciones descriptivas el sentimiento de la naturaleza encuentra un modo de expresión más directo e inmediato, deliberadamente sencillo pero con resonancia lírica más íntima.

He aquí un fragmento de la poesía $A$ la luna:

En lo escondido de la enramada o de la hojosa selva, el suspiro de un alma cariñosa anuncia tu presencia o el flauteo del triste ruiseñor, y en las ruinas de la gótica torre, el ave hermana 
de la noche y el duelo, recordando

al miserable el frío de la tumba

y el reposo eternal. ¡Cuánto recrea

al alma dolorida la blandura

de tu rayo benigno! Si atraviesas

la espesura del bosque silencioso,

templo del culto que a tu amor dedico, ya para mí no hay soledad. El aire es vida al corazón. Ni tú pareces un astro superior que enseñorea la mansión terrenal, sino una amiga, mi compasiva hermana, que, velada en pompa melancólica, desciendes a ver mis males y a llorar conmigo. Vuelve entonce a mi espíritu abatido un rayo de consuelo: libre gozo del aire que tu aliento vivifica, en él vertiendo sueños, ilusiones, descanso y paz. Los árboles sonríen con tranquilo mecer; suena en las ramas el tímido soplar del aura leve, cual si los genios a la tierra absorta misteriosos secretos revelasen.

De La Oliva, donde el autor evoca un lugar de su región natal que lleva ese nombre, es este pasaje:

De mi inefable arrobo me sacaron lentos silbidos, trémulos murmullos con que en remoto abrigo sus amore cantaba el ruiseñor. Torno la vista y doquier la fijaba, muy más lejos la gustosa armonía resonaba. Empeñado en seguirla, del hojoso lindero me aparté, cual hechizado por misterioso influjo, y medio hundide entre llanuras de movible arena, vi sombrear un retirado grupo de acopados enebros y de alisos. Su sombra apenas protegió mi frente, cuando cesó la mágica dulzura del canto de las aves, y a medida que en el frondoso asilo me emboscaba, más triste era el silencio y más profundo. ¡Tan extraña visión fué en aquel sitio la presencia del hombre!

En El otoño del No me olvides de 1824, composición meditativa a la manera de Meléndez Valdés, el tono moralizador es mucho más acusado que en La Oliva; allí la contemplación de las bellezas campes- 
tres casi no sirve más que de pretexto para una declamación contra los males de la ciudad; aquí la huída hacia la naturaleza significa la vuelta al primitivo ser, y en vez de un himno a la razón, ahora es el vuelo osado de la imaginación lo que se exalta:

¿Es ilusión volátil, o en las selvas hay un oculto espíritu que ampara la mente pensadora, y cuando rompe de la ciudad el fascinado yugo y en los bosques se goza, torna en ellos al primitivo ser? Ría quien busca mentida ciencia en rotos pergaminos o destrozando el palpitante seno del moribundo can. Ese no alcanza de la imaginación el vuelo osado, y mientras más el natural misterio se afana en descubrir, más muda y fría natura le parece, cual oculta la sensitiva sus modestas hojas si las toca un osado. Yo, que adoro su poder invisible, y en la anchura de sus obras inmensas sólo indago lo que me hará feliz, feliz me creo cuando en sabrosa soledad me libro a vagos pensamientos que en el alma naturaleza excita; tal cediendo al muelle impulso, el ramo que abatiera bramando el aquilón, sobre las olas del quieto lago, plácido se mece, ya acariciando la frondosa orilla, ya ocultando sus hojas en la espuma que el vientecillo eleva y desbarata.

$\ldots \ldots \ldots \ldots \ldots$ Y pues me es dado

hallar amor y sentimiento y vida

allí do sus designios admirables grabó Naturaleza, de sus obras contemplador celoso y reverente, juré también loarlas, y en mis rimas ceder a la impresión de sus encantos.

Aún hay aquí difusas reminiscencias prerrománticas -Young, Thomson, Delille- que no eran desconocidas en la poesía española. Pero parece indudable que el autor de estos versos había leído también a otro "reverente contemplador de la naturaleza", Wordsworth, a quien mencionaba poco después elogiosamente en su Correo Literario y Politico de Londres.

- Enero de 1826, pág. 17. 
No se limita a esto el interés del No me olvides de 1825 . El Forget me not, de donde procedían gran parte de las composiciones en prosa de su gemelo español, ofrece una buena muestra de la sensibilidad literaria del momento. Dirigido principalmente a un público femenino -que Ackermann había fomentado como nadie hasta entonces en Inglaterra-, y redactado en no escasa proporción por varias de las escritoras más renombradas de aquellos días, el tono romántico sentimental, aunque no siempre de buena ley, es el predominante, tanto en las poesías como en las breves narraciones en prosa. De éstas el Forget me not de 1825 contiene, por ejemplo, la historia pasional de una joven suicida, un cuento fantástico alemán, una leyenda del Oriente, y un cuento de asunto medieval. El No me olvides del mismo año, que las reproduce, da todavía mayor impresión de época por haber intercalado Mora de propia minerva una caricatura de narración romántica titulada $L a$ partida, que trata de los amores de una joven gallega con un granadero francés apasionado lector de Malvina, "nada menos que de Malvina, como si dijéramos el prototipo de la exaltación, el modelo de la melancolía, el nec plus ultra de la pasión vehemente, del arrebato de los afectos y el paroxismo del cariño simpático. Amelia infirió inmediatamente que su alojado era un paladín de los de la mesa redonda, un amante de la contemplación, un Chactas, un Werther".

Pero sobre todas las composiciones del libro, de muy desigual mérito, destaca por su belleza una en prosa, El Alcázar de Sevilla, publicada también en el almanaque inglés del mismo año, y reproducida parcialmente con un elogioso comentario en la Literary Gazette $^{10}$. Evocación romántica del Alcázar que se inicia con una descripción de los famosos jardines, y nos transporta luego a los tiempos del rey don Pedro entre figuras y episodios legendarios, como el de la calle del Candilejo, tratado más tarde por Rivas -que estaba en Londres cuando apareció este No me olvides-, para terminar con la historia del tesoro escondido en la Casa del Duende. La atmósfera local y la sensación de lejanía surgen en este caso del mismo fondo nostálgico. El autor es un desterrado que se acerca imaginativamente al lugar nativo no sólo para evocar el pasado histórico, sino para revivir, transido de dolor, su propia existencia juvenil.

Bajando estoy el valle de mi vida, y todavía se fijan mis pensamientos en aquellas calles estrechas, sombrías y silenciosas, donde respiraba el aire perfumado que venía como revoloteando de las vecinas espesuras; donde los pasos retumbaban en los limpios portales de las casas: donde todo respiraba contentamiento y bienandanza; modesto bienestar, ensanchado por la

${ }^{10} 16$ de octubre de 1824. (Muchas publicaciones inglesas se ponían a la venta con anterioridad a la fecha de impresión). 
alegría y por la mesura de los deseos; honrada mediocridad, que no se atraía el respeto por la opulencia ni por el poder, sino por el pundonor heredado. Ya empiezan a desvanecerse, como meras ilusiones, los objetos que me rodean, y no sólo los recuerdos, sino las sensaciones externas que recibí en aquella época bienhadada se despiertan como realidades en mi fantasía. ¿Qué es lo que queda de las cosas humanas sino estos vestigios mentales, estas impresiones penosas y profundas que como heridas mal cerradas en el corazón del desterrado, echan sangre cada vez. que se las examina?

El sevillano que escribió esta página no era otro que Blanco White. En el No me olvides español, donde es normal el anonimato, no figura su nombre; pero en el inglés, The Alcazar of Seville se imprime como obra del autor de las Doblado's Letters, o sea de las Letters from Spain. Ahora bien, el texto español no parece traducido, aun admitiendo en Mora dotes excepcionales de traductor; ni siquiera como versión del propio Blanco. Si acaso tradujo sería, en este caso, del español al inglés. El texto original debió redactarlo en su lengua nativa ${ }^{11}$.

En esta breve composición en prosa está todo Blanco con su dolor de expatriado, su sensibilidad de inadaptable, su espíritu imaginativo. La visión de la antigua Sevilla no es sino la huída hacia un mundo mágico y feliz, alejado del presente. Para ese vuelo de la fantasía no hace ninguna falta la erudición; la leyenda vale más que la historia:

$\mathrm{Ni}$ siquiera he tomado en las manos un solo libro de los que contienen la historia de mi ciudad nativa. ¿Qué más libros que el Alcázar? Para mí aquél era un sitio de encanto. Los cuentos tradicionales que tantas veces había oído en los dulces labios que me enseñaron el habla de Castilla, habían producido este efecto en mi imaginación. Dábaseme un bledo de sus actuales habitantes, ni veía otros en el Alcázar que las sombras de los moros y españoles que habían residido allí en las eras del amor y la caballería.

${ }^{1 i}$ El examen de los textos es en sí mismo poco concluyente, entre otras ràzones porque el español de Blanco abunda en anglicismos. Pero hay otra narración suya que no ofrece dudas en cuanto a su redacción original, Las intrigas venecianas, publicada en las Variedades en 1825 , y que reaparece en versión inglesa en el Forget me not de 1826, cuando Blanco, ya en Oxford, habia abandonado la amena literatura y el español. Creo no equivocarme suponiendo que el Alcázar de Sevilla se debió al choque emocional recibido por Blanco al encontrarse en Londres al cabo de los años con el músico y cantante Manuel García, amigo de la infancia. Su naturaleza era altamente impresionable, según Alberto Lista, que tenía mótivos para conocerle bien. Todavía al reseñar poco después este No me olvides del 25 , Blanco, mientras guarda silencio sobre su propia narración, se refiere a la vida de García que allí figura, redactada por Mora, diciendo que le ha renovado "recuerdos de su juventud y su patria". 
Los recónditos jardines son el hortus clausus donde buscaba apartamiento y liberación el alma roussoniana de Blanco, oprimido por un ambiente hostil que no podía comprenderle. Ahora describe los vallados de arrayán, los cuadros de flores, los juegos de las fuentes, cuyos surtidores armoniosos sigue escuchando todavía en silencioso éxtasis. Pero no es la descripción de un cuadro "bello". Blanco no usa de colorido pintoresco, pero destaca lo diferencial y característico. La peculiar belleza de aquellos jardines puede dejar indiferente al extraño; el andaluz percibe sin embargo su misterioso encanto:

No faltan viajeros remilgados y descontentadizos que miran estos objetos con afectado desdén; los andaluces empero, adoctrinados por el clima y por las cualidades de la tierra que habitan, no buscan delicias rurales en el recinto de una ciudad, ni bosques majestuosos en llanuras tostadas, ni césped aterciopelado debajo de una atmósfera ardiente, que no dejaría trazas de verdor si no fuera por la tenacidad de algunas plantas y por los arroyos artificiales que las riegan: lo que anhelan es la frescura de la sombra, la fragancia de las auras, los murmullos de las fuentes; el hálito de los naranjos, que casi trastorna los sentidos; la espesa, aunque invisible nube de esencias que las rosas exhalan; los suspiros del vendabal, y los muy más suaves flauteos del ruiseñor. Estos placeres son harto diferentes de los que se gozan en la fría y vasta soledad de un parque; pero ¡oh, cuánto realce les da la misteriosa estrechez de un jardín morisco!

Varias son las partes del Alcázar de Sevilla que parecen revelar el desgarramiento interior de Blanco, aun sin la terminante declaración del principio. ¿Qué puede significar aquel grito final de la morisca Zuleima en la leyenda de la Casa del Duende sino la propia voz de quien en lo hondo de su ser hubo de proferir, con toda su devoción filial, el mismo clamor angustioso?

A mediados de diciembre, cuando las lluvias continuas anunciaban una próxima crecida del Guadalquivir, y no había alma viviente que pusiese los pies en la calle después de oraciones, Fátima hizo los preparativos que debían ayudarla en la empresa que había meditado. Hízose de una cuerda y de un canasto, y cerca de las doce de la noche señalada para llevar adelante la hechicería, se dirigió a tientas hacia el zaguán, llevando por la mano a Zuleima, que temblaba como la hoja en el árbol. Dan las doce en el reló de la catedral, cuyo sonido en las calladas horas de la noche retumba en todos los ámbitos de la ciudad. Dos minutos después se oyeron los melancólicos golpeos de la plegaria, y cuando éstos cesaron quedó todo en el más profundo silencio, que de cuando en cuando interrumpían los aguaceros y las ráfagas. Fátima, desasiéndose de las frías manos de Zuleima, 
hirió un pedernal, encendió un cabo de vela verde de una pulgada de largo y lo colocó en un linterna. Apenas dieron los primeros rayos de luz en el pavimento, cuando se abrió éste cerca de donde estaban la madre y la hija.

Dominando sus temores desciende ésta a la bóveda llena en el fondo de monedas de oro. Empieza a llenar la canasta, pero de repente la luz de la vela se apaga, la cuerda desaparece.

Oyóse un quejido lastimero. Lanzábalo la cuitada Zuleima, sepultada ya en montones de oro. Volvió a quedar todo en tinieblas; la infeliz madre buscaba a tientas la boca de la bóveda, pero en vano. Había cesado el encanto, y el suelo había vuelto a su estado primitivo. Hiérelo repetidas veces con el pie, y más crece su angustia cuando un eco pavoroso retumba en la concavidad cerrada para siempre. Golpea con fuerza sobre los guijarros del piso, hasta que sus manos se entumecen. Arrójase casi exánime al suelo, y cuando recobra por algunos momentos el sentido, oye en lo profundo la voz plañidera de la hija: "Madre mía, madre mía, no me degéis a oscuras ..."

Si puede dudarse de la significación personal de esta página, hay que admitir por lo menos su relación con las ideas literarias de Blanco. El Alcázar de Sevilla debió escribirse al mismo tiempo o muy poco después de publicar su autor a mediados de 1824 unos artículos sobre Juan Manuel y el "placer de las imaginaciones inverosímiles"12. A la defensa teórica de lo sobrenatural y fantástico en la literatura, hecha concretamente contra los neoclasicistas españoles contemporáneos, seguía, digamos así, la demostración práctica. Y hasta hay un eco en el Alcázar de la actitud crítica de quien lo escribió. Don Antonio Montes de Oca, el supuesto caballero sevillano que va revelando al joven alter ego de Blanco la historia de la ciudad, expresa el deseo de que se coleccionen los cuentos de hechicería conservados por la tradición local; lo que le da pie para relatar la leyenda de la Casa del Duende. Y como su interlocutor le interrumpa diciéndole que tal historia debe pertenecer, por el nombre dado a la casa, "a la parte ridícula del mundo de los espectros", don Antonio le contesta adoptando los principios del esteticismo romántico: "Nada de eso, la historia, falsa o verdadera, es trágica e interesante". Valía, pues, la pena contarla, independientemente de su moralidad o de su verdad.

El No me olvides de 1825 , tan olvidado a pesar de su título, merece, pues, no obstante las traducciones o adaptaciones que contiene, ocupar un puesto nada desdeñable en los orígenes del romanticismo español, cuyo primer núcleo se encuentra entre los emigrados en

${ }_{12}$ Variedades, I, págs. 413-418; New Monthly Magazine, XI, págs. 28-35 y $97^{-103}$. 
Londres, bien que su promotor y representante más destacado, Blanco White, no pertenece al grupo liberal de 1823 .

Hasta 1824 la historia del romanticismo en España se había reducido casi exclusivamente a la polémica entre el alemán Boehl de Faber y Mora, iniciada en Cádiz en 1814 y reanudada de 1818 a 1820, y a un par de artículos del italiano Monteggia y López Soler en El Europeo de Barcelona, cuya corta vida (octubre de 1823 a abril del año siguiente) interrumpió la reacción absolutista, sin que la revista tuviera la menor repercusión en las letras castellanas. El 1824 presenta nuevas y más importantes aportaciones, en primer término los escritos de Blanco en las Variedades ${ }^{\mathbf{1 3}}$, sin que pueda prescindirse de sus artículos en inglés y los de Mora por cuanto se refieren a temas españoles con un sentido opuesto al clasicista.

Pero todo esto no pasaba de ser literatura crítica; con el No me olvides de 1825 tenemos por primera vez, aunque en escasa proporción, prosa y verso románticos debidos originalmente a pluma espanola.

Princeton University.

ViGente LLORENS

${ }^{13}$ En realidad, las Variedades anteceden al Europeo. El número de prueba de la revista de Blanco apareció en enero de 1829 . El sumario de la parte literaria es ya revelador: poesía provenzal, Walter Scott, crónicas medievales, romances antiguos y Shakespeare. 